\title{
MULTI-HAZARD PERFORMANCE OF REINFORCED CONCRETE DRY CASKS SUBJECTED TO CHLORIDE ATTACK AND TIP-OVER IMPACT
}

${ }^{1}$ Mohammad Hanifehzadeh, ${ }^{2}$ Bora Gencturk, ${ }^{3}$ Arezou Attar, ${ }^{4}$ Kaspar Willam

1 Graduate Research Assistant, Department of Civil and Environmental Engineering, University of Houston, Houston, TX, USA.

2 Assistant Professor, Sonny Astani Department of Civil and Environmental Engineering, University of Southern California, 3620 S. Vermont Avenue, KAP 210, Los Angeles, CA 90089-2531, Corresponding author, Phone: (213) 821-1036, Fax: (213) 744-1426, E-mail: gencturk@usc.edu.

3 Graduate Research Assistant, Department of Civil and Environmental Engineering, University of Houston, Houston, TX, USA.

4 Professor, Department of Civil and Environmental Engineering, University of Houston, Houston, TX, USA.

\section{Abstract}

Vertical concrete dry storage systems (or dry casks) are circular containers made of steel and/or reinforced concrete, specifically developed for storing spent nuclear fuel (SNF). In the United States, dry casks are designed for a service life of 40 years; however, in the absence of a permanent repository for storage of SNF, it is expected that the service life of dry casks will be extended well beyond their initially intended period. Tipping-over is considered as one of the hypothetical accident conditions. The consequence of such an incident may be more severe if the structural integrity of the dry cask is compromised during the extended service life due to steel corrosion and related material degradation. In this study, structural performance of a $1 / 3$-scale vertical concrete cask is evaluated under combined corrosion-induced damage and tip-over impact. The results are compared with those from a control cask which is only subjected to impact but no corrosion-induced damage. The impact response of both casks in terms of acceleration, velocity, and strain was measured and compared. The damage after testing is investigated in terms of cracking and deformation to identify the failure modes for each cask and the effects of aging on the structural performance.

Keywords: Concrete Cask, Tip-over Impact, Nuclear Waste, Spent Nuclear Fuel, Steel Corrosion 


\section{Introduction}

Dry cask storage systems are intended to provide temporary onsite storage of spent nuclear fuel (SNF). The SNF assemblies, composed of several fuel rods, are placed in SNF pools for cooling and radiation shielding for several years after being removed from the nuclear reactor. As SNF pools started to reach their capacities in the early 1980s, utilities began looking for alternatives to increase the on-site storage capacity of SNF. Dry cask systems emerged as a convenient temporary storage option. After a minimum of one year storage in the SNF pool (U.S. NRC, 2016), the fuel temperature and radioactivity decreases sufficiently for the SNF to be removed from the pool and placed in a cask. The first cask installation was licensed by the United States Nuclear Regulatory Commission (NRC) in 1986 at the Surry Nuclear Power Plant in Virginia. Since then, the cask sites have constantly increased exceeding 60 sites around the United States at the time of writing of this paper. In the canister-based cask designs, the SNF is sealed in a cylinder filled with an inert gas, called the canister, and then the canister is placed in the cask with a thick outerpack made of steel, concrete, or both, to provide further radiation shielding and protection against mechanical loading. There also exists non-canistered cask designs where the SNF assemblies are directly inserted into the cask without a separate sealed canister. Both horizontal and vertical cask configurations are used in the United States. In this paper, a vertical, canister-based configuration is investigated for its vulnerability to tip-over impact event. A typical configuration of a vertical concrete storage system is shown in Figure 1.

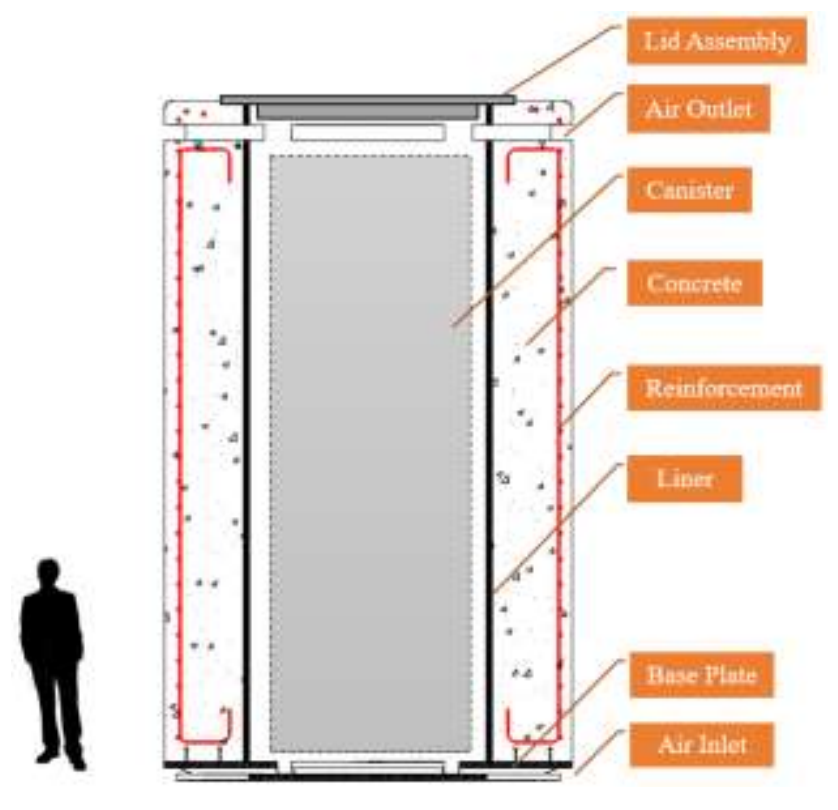

Figure 1 Typical configuration of vertical dry storage system.

A tip-over event is a hypothetical accident which may happen during the regular handling or in the case of an extreme event such as a strong earthquake, tornado or an explosion. Based on the standard review plans developed by the U. S. NRC, the structures should be evaluated under normal and offnormal environmental conditions as well as under hypothetical accidents (NUREG, 2000). Most vertical casks are freestanding on a concrete pad. This leads to stability concerns in terms of sliding and tippingover in seismic areas which threatens the safety of the canister and the fuel rods. The most important parameter for SNF integrity under impact loading is the induced g-load, which could be used as a measure for performance evaluation and canister design. 
Over the past three decades, several impact tests have been performed mostly on the transfer casks (used to transfer the canister from a storage to a transportation cask). In the United States, the first series of testing including impact and fire tests were performed in 1970s at Sandia National Laboratories (Shappert, 1970). The Oak Ridge National Laboratory built an impact pad the tower shielding facility, which has a large lift capacity, sufficient to elevate a 75-ton weight to a height of about $60 \mathrm{~m}$. In 1974, the first cask specimens weighting from $2700 \mathrm{~kg}$ to $5400 \mathrm{~kg}$ were dropped from a height of $9 \mathrm{~m}$ onto a steel impacting surface (Shappert and Ludwig, 2004). Vecchio and Sato (1988) performed a study on $9 \mathrm{~m}$ free drop on ridged surface and $1 \mathrm{~m}$ drop onto a steel pin using a half-scale concrete cask weighting 6.6 tons. They observed significant cracking in the impact area and rupturing of hoop reinforcement in the 9 $\mathrm{m}$ drop test. Several full-scale impact tests were performed from 2004 to 2008 consisting of drop and aircraft crush test on steel storage casks by the Central Research Institute of Electric Power Industry in Japan (Kato and Saegusa, 2001). Furthermore, a series of drop tests were performed on 1/3 scale models of steel dual purpose casks produced by Hitachi in 2000s (Shimizu and Hoshikawa, 2004). The results from these studies were used for improvements toward an optimal design. To the knowledge of the authors, the only published tip-over test on a concrete cask (in this case, a $1 / 3$ scale model) is presented by Kim et al. (2006) in which the structural integrity of the canister was also investigated via liquid penetrant testing and an ultrasonic method. Further, the tip-over impact performance of vertical concrete casks subjected to environmental degradation has not been investigated before.

Corrosion damage is a major concern for reinforced concrete structures which in the long-term can cause deterioration of the steel, concrete and the steel-concrete interface. The rebar is initially protected by alkalinity of the concrete pore solution, which results in a passive film on the surface. The presence of the chloride ions could suppress the passive film and produce corrosion products (iron oxide and hydroxides) which have a volume twice to four times that of steel. The expansion due to development of the products initiate tensile stress and eventually grow cracks on the concrete surface. This issue becomes more significant for structures located in coastal environments such as nuclear power plants. The corrosion may reduce the area of steel reinforcement, deteriorate the bond between the rebar and surrounding concrete and also result in surface cracks and spalling. Corrosion results in a reduced service life and structural integrity. The effect of steel corrosion on the service life of the reinforced concrete structures has been studied in various research programs (Song and Saraswathy, 2007, Spencer et al., 2014, Ahmad, 2003, Liu and Weyers, 1998, Schießl and Raupach, 1997, Ann and Song, 2007, Ghazanfari and Manafpour, 2016). However for casks, the studies have mostly focused on the corrosion of the canister (Tani et al., 2009, Spencer et al., 2014, Marsh and Taylor, 1988, Shoesmith, 2006). In this study, reinforcement corrosion in concrete is considered as the main source of material degradation and the structural integrity in the case of tip-over accident is assessed. To our knowledge, no prior research investigated the multi-hazard performance of dry casks subjected to environmental aging followed by a tip-over impact, which is now more seriously considered as a potential scenario due to extended use of dry casks in the absence of a permanent facility for storage of commercial SNF in the United States. In order to address this issue, first a concrete mixture was developed to accelerate the long-term aging of reinforced concrete due to corrosion. Two scaled cask model were fabricated, one using normal concrete (control cask) and another one using the corrosive mixture (aged cask). Corrosion progression of the aging specimen was monitored over a two year period. After the two years, the two specimens were subjected to tip-over events and a comparative structural performance evaluation was performed. 


\section{Experimental Program}

Two 1/3 scaled cask models were designed and fabricated. Calcium chloride was added to one of the concrete mixtures (here called corrosive concrete) to simulate the long-term steel corrosion. A normal concrete mixture was used for the second (control) specimen. The aging process was monitored via destructive and non-destructive methods over a two year period. The details on the non-destructive testing of the casks are provided in a previous publication (Attar et al., 2016). Three tip-over tests were performed after two years followed by damage evaluation of the specimens.

\subsection{Design and fabrication of the specimen}

A detailed review of the most commonly used cask in the United States was performed. Table 1 summarizes the main dimensions of the casks commonly used by the United States nuclear power industry. Typical values were chosen for the weight and dimensions of the cask model using a scaling factor of 2.83. More realistic behavior of the structure may be obtained from full-scale tests; however, the specimen dimensions and weight are in most cases limited due to the cost of fabrication and capabilities of the testing facilities. Reduced-scale models are commonly used for experimental investigation of large structures. The main objective of the scaling procedure is to reduce the size and weight of the specimen without losing the main structural characteristics. The average values were scaled using the geometric scaling factor of 2.83 and the final dimensions were determined for the cask height, liner thickness, outer diameter and concrete thickness with due consideration of the constructability issues (e.g., available discrete steel plate thicknesses and reinforcing steel sizes). The scaled dimensions used in the physical model casks are provided in Table 1.

Table 1 Main dimensions of the most common vertical concrete casks used in the United States.

\begin{tabular}{|c|c|c|c|c|c|}
\hline Vertical Concrete Cask & Vendor & Height (mm) & $\begin{array}{c}\text { Outer } \\
\text { Diameter } \\
(\mathrm{mm})\end{array}$ & $\begin{array}{c}\text { Liner } \\
\text { Thickness } \\
(\mathrm{mm})\end{array}$ & $\begin{array}{c}\text { Concrete } \\
\text { Thickness } \\
(\mathrm{mm})\end{array}$ \\
\hline $\begin{array}{l}\text { MAGNASTOR CC1 \& } \\
\mathrm{CC}^{1}\end{array}$ & NAC International & 5723 & 3454 & 44.5 & 673 \\
\hline MAGNASTOR CC3 & NAC International & 5545 & 3454 & 76.2 & 643 \\
\hline VSC- $24^{2}$ & $\begin{array}{l}\text { BNG Fuel Solutions } \\
\text { Corporation }\end{array}$ & $\begin{array}{c}5718,5410 \\
5000\end{array}$ & 3353 & 44.5 & 737 \\
\hline HI-STORM ${ }^{3}$ & Holtec International & 5867 & 3353 & 51 & 699 \\
\hline NAC-UMS & NAC International & $5309-5740$ & 3454 & 63.5 & 711 \\
\hline VSC $-17^{2}$ & $\begin{array}{l}\text { BNG Fuel Solutions } \\
\text { Corporation }\end{array}$ & 5740 & 2667 & 89 & 508 \\
\hline Average & - & 5607 & 3416 & 56 & 692 \\
\hline Scaled Average & - & 1979 & 1206 & 19.8 & 244 \\
\hline Physical Model & - & 2030 & 1220 & 16 & 238 \\
\hline
\end{tabular}

In order to represent the SNF canister inside the cask, an assembly of eight solid steel rods packed inside a steel tube was used. The individual components of the model cask are illustrated in Figure 2. The 
fabrication process of the scaled physical cask models is shown in Figure 3. The key dimensions for each component of the model are summarized in Table 2. The lid was fixed in place using six high strength bolts once the tube is placed inside the overpack. The steel reinforcing cage was made of U.S. designation No. $3\left(71 \mathrm{~mm}^{2}\right.$ nominal area) bar with center to center spacing of $130 \mathrm{~mm}$ and $75 \mathrm{~mm}$ in circumferential and vertical directions, respectively. A concrete cover of $40 \mathrm{~mm}$ was provided according to $\mathrm{ACl}$ 318-14 (2014). The weight of each component and total weight of the specimen is provided in Table 3.

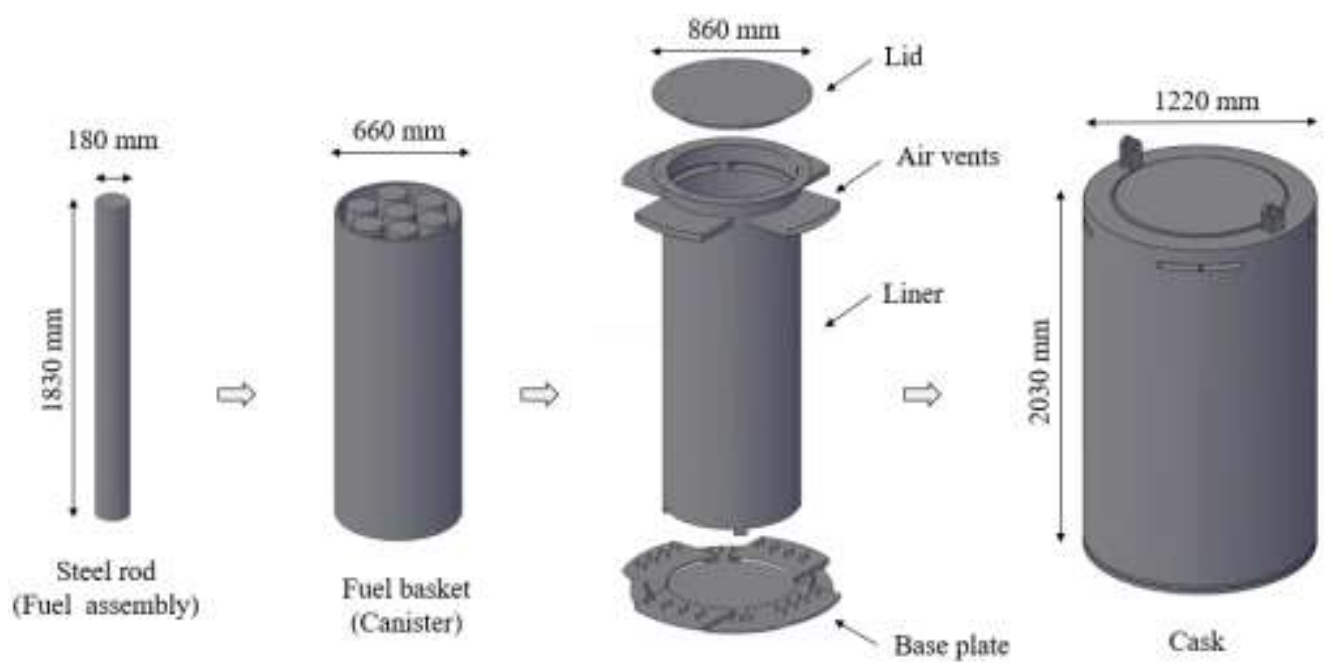

Figure 2 Components of the tested physical cask models.

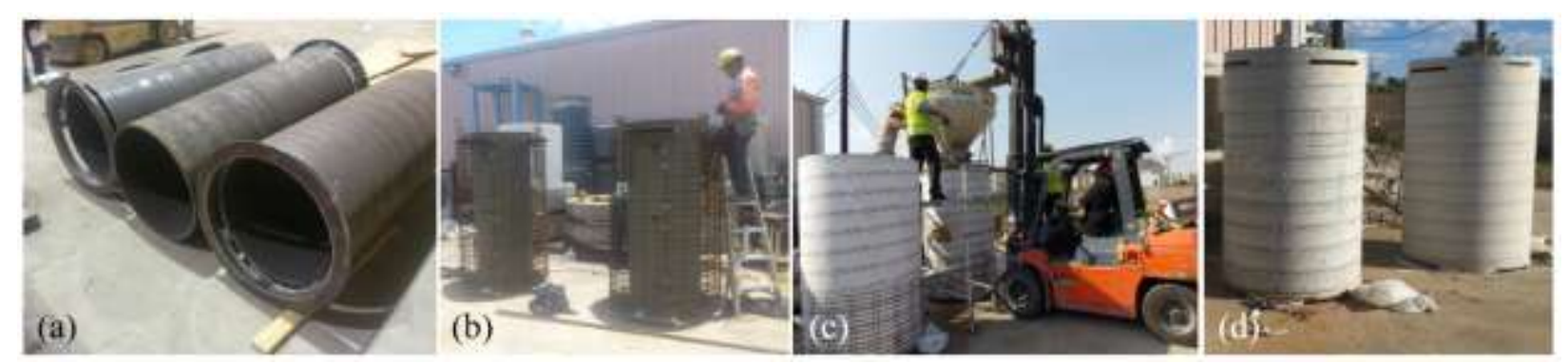

Figure 3 Fabrication of the specimens (a) steel parts (b) reinforcement (c) concrete casting (d) fabricated casks.

Table 2 Dimensions of the model components.

\begin{tabular}{|l|c|c|}
\hline Model Part & Prototype Size $(\mathrm{mm})$ & Scaled Model Size $(\mathrm{mm})$ \\
\hline Cask Length & 5723 & 2030 \\
\hline Cask Outer Diameter & 3454 & 1220 \\
\hline Concrete Thickness & 673 & 238 \\
\hline Liner Length & 5558 & 1969 \\
\hline Liner Inner Diameter & 2019 & 710 \\
\hline Liner Thickness & 44 & 16 \\
\hline Lid Plate Diameter & 2019 & 860 \\
\hline Lid Plate Thickness & 19 & 6 \\
\hline Base Plate Thickness & 76 & 19 \\
\hline Base Diameter & 3454 & 1220 \\
\hline Air Vent & $114 \times 1300$ & $47 \times 457$ \\
\hline
\end{tabular}


Table 3 Weight of each component.

\begin{tabular}{|l|c|}
\hline Parts & Weight $(\mathrm{kg})$ \\
\hline Steel Parts (Liner, Base, Vents) & 832 \\
\hline Concrete Segment Overpack & 3640 \\
\hline Lid Assembly & 87 \\
\hline Canister Assembly & 3260 \\
\hline Total & 7819 \\
\hline
\end{tabular}

Additionally, a concrete pad was built using a concrete mixture with $48 \mathrm{MPa}$ compressive strength (compare to $40.4 \mathrm{MPa}$ and $28.8 \mathrm{MPa}$ for control and aged casks) and a high reinforcement ratio to minimize damage. The strain gages installed on the pad reinforcement (not included in the instrumentation discussion above) showed less than $10 \%$ of the yielding strain during the impact tests. Additionally the pad surface was inspected after each test and no cracking was observed. The top $1.0 \mathrm{~m}$ of the loose subgrade soil was replaced with a $0.2 \mathrm{~m}$ gravel and compacted dynamically prior to the test to minimize the plastic deformation of the soil.

\subsection{Concrete mixtures for accelerated aging and material properties}

Under normal conditions, it will take several years for chloride ions to diffuse into the concrete and (or carbonation front to) reach the reinforcing steel, initiate corrosion, and cause a noticeable amount of degradation. There are methods for accelerating the corrosion process such as adding chloride directly into the concrete mixture at the time of mixing (Attar et al., 2016, Lee et al., 2000), passing electrical current through the reinforcement (Galvano static method) (Abosrra et al., 2011, Cheng et al., 2005), and using an artificial environmental exposure that is more conducive to corrosion (i.e., high temperature and wet-dry cycles) (Yuan et al., 2007, Şahmaran and Li, 2009). However, most of these techniques are very difficult to apply in large-scale investigations. Addition of chloride solution to the concrete mixture starts the corrosion process immediately after the casting (Zhou et al., 2014). In this case, the required time for diffusion of the ions through the concrete cover in natural conditions is bypassed. Therefore, adding chloride to the fresh concrete mixture was chosen here to accelerate the aging. A series of tests were performed to investigate the influence of adding different amount of chloride to the mixture. The objective was to identify the maximum chloride content without making a significant impact on setting time and compressive strength of concrete. A higher chloride content was desired to achieve a quick corrosion-induced degradation in the reinforced concrete overpack. Accordingly, $4 \%$ chloride ion by weight of cement was determined. Higher amounts of chloride was found to reduce the setting time to an impractical level to allow placing of the concrete. The chloride ions were added to the fresh concrete in proper amount in the form of $\mathrm{CaCl} 2$ flakes. The concrete mixtures were prepared by using Type I/II cement and Type $\mathrm{F}$ fly ash. A fine to coarse aggregate ratio of 0.89 and a water to cement ratio of 0.45 was used for the mixtures. Master Glenium $7500 \mathrm{~N}$ (superplasticizer) and Master Pozzolith 200 (normal plasticizer) were used as water-reducing admixture (BASF, 2016). The latter was also used to control the setting time. Table 4 shows the concrete mixture designs for the control and aged casks. 
Table 4 Concrete mixture design for control and aged specimen (per $0.04 \mathrm{~m}^{3}$ ).

\begin{tabular}{|l|c|c|c|}
\hline Material & Unit & Control & Corrosive \\
\hline Cement & $\mathrm{kg}$ & 12.84 & 12.84 \\
\hline Type F Fly Ash & $\mathrm{kg}$ & 4.26 & 4.26 \\
\hline 3/8" Pea Gravel & $\mathrm{kg}$ & 48.67 & 48.67 \\
\hline River Sand & $\mathrm{kg}$ & 43.09 & 43.09 \\
\hline Water & $\mathrm{kg}$ & 5.72 & 5.72 \\
\hline Pozzolith 200 & $\mathrm{ml}$ & 45.84 & 45.84 \\
\hline Glenium 7500N & $\mathrm{ml}$ & 91.97 & 91.97 \\
\hline Additional Chloride $\left(\mathrm{CaCl}_{2}\right)$ & $\mathrm{kg}$ & 0.0 & 0.78 \\
\hline
\end{tabular}

Tensile testing was performed on the steel reinforcement, and steel plates used for the fabrication of the liner and lid according to ASTM A370-16 (2016) and ASTM E8/E8M-16a (2016), respectively. The steel used for the base-plate has the same nominal strength as the lid and liner. Since the base-plate does not have significant structural contribution in the tip-over test, the material properties provided by the supplier were taken and no additional coupon test was performed. The results are provided in Table 5 .

Table 5 Material properties for steel parts.

\begin{tabular}{|l|c|c|c|c|}
\hline \multicolumn{1}{|c|}{ Steel Part } & Component & $\begin{array}{c}\text { Yield Stress } \\
(\mathrm{MPa})\end{array}$ & $\begin{array}{c}\text { Ultimate } \\
\text { Stress (MPa) }\end{array}$ & $\begin{array}{c}\text { Modulus of } \\
\text { Elasticity (GPa) }\end{array}$ \\
\hline Rebar \#3 & Steel Reinforcement & 546 & 817 & 190 \\
\hline $6.4 \mathrm{~mm}$ Plate & Lid & 356 & 501 & 181 \\
\hline $15.9 \mathrm{~mm}$ Plate & Liner & 310 & 467 & 181 \\
\hline
\end{tabular}

Table 6 shows the mechanical properties of the control and corrosive hardened concretes obtained according to the relevant ASTM standards.

Table 6 Physical and mechanical properties of concrete.

\begin{tabular}{|l|c|c|c|}
\hline \multicolumn{1}{|c|}{ Property } & Control & Corrosive & ASTM Standard \\
\hline 28 Days Compressive Strength (MPa) & 34.1 & 25.9 & C39 (ASTM, 2016) \\
\hline 365 Days Compressive Strength (MPa) & 40.4 & 28.8 & C39 (ASTM, 2016) \\
\hline 28 Days Split Tensile Strength (MPa) & 4.5 & 3.1 & C496 (ASTM, 2004) \\
\hline 365 Days Split Tensile Strength (MPa) & 4.5 & 3.4 & C496 (ASTM, 2004) \\
\hline 28 Days Young's Modulus (GPa) & 25.3 & 20.5 & C469 (ASTM, 2014) \\
\hline Density $\left(\mathrm{gr} / \mathrm{cm}^{3}\right)$ & 2.33 & 2.35 & C138 (ASTM, 2016) \\
\hline
\end{tabular}

\subsection{Pre-existing damage due to corrosion}

Extensive cracking was observed on the surface of the aged cask after two years of accelerated aging (see Figure 4). The first crack was observed approximately after 120 days after casting. The crack pattern is influenced by cover thickness and steel bar position (Cabrera, 1996). On the surface of the cask, the 
cracks were mostly formed in the same direction with the circumferential and longitudinal reinforcement. Prior to impact testing, the crack width were measured at 23 points on the entire surface of the cask. At least 3 measuring points were picked over all major cracks. The crack width varied from $0.1 \mathrm{~mm}$ to $1.46 \mathrm{~mm}$ with an average of $0.33 \mathrm{~mm}$. Note that according to $\mathrm{ACl}$ (2003), the recommended maximum crack width in seawater exposure condition is $0.15 \mathrm{~mm}$. A half-cell potential measurement was also performed on the entire surface of the cask in accordance with ASTM C876 (2015) regularly over the two year period of monitoring. An average value of $-500 \mathrm{mV} / \mathrm{CSE}$ was measured throughout the aging period. A comparison of this value with the threshold of $-350 \mathrm{mV} / \mathrm{CSE}$, indicates that the probability of corrosion was more than $90 \%$ during this period. The area reduction was also measured after the tip-over test to evaluate the level of corrosion. The rebar was extracted from the concrete at select locations and the diameter of the rebar was measured, using calipers with a precision of 0.0001 $\mathrm{mm}$, at twenty different locations on two rebar and the smallest diameter was about $9.07 \mathrm{~mm}$, which compared to the original diameter of $9.52 \mathrm{~mm}$, indicates a $9 \%$ decrease in the cross-sectional area. More details regarding the non-destructive testing and long-term monitoring of the casks is available in Attar et al. (2016) and Attar (2016).

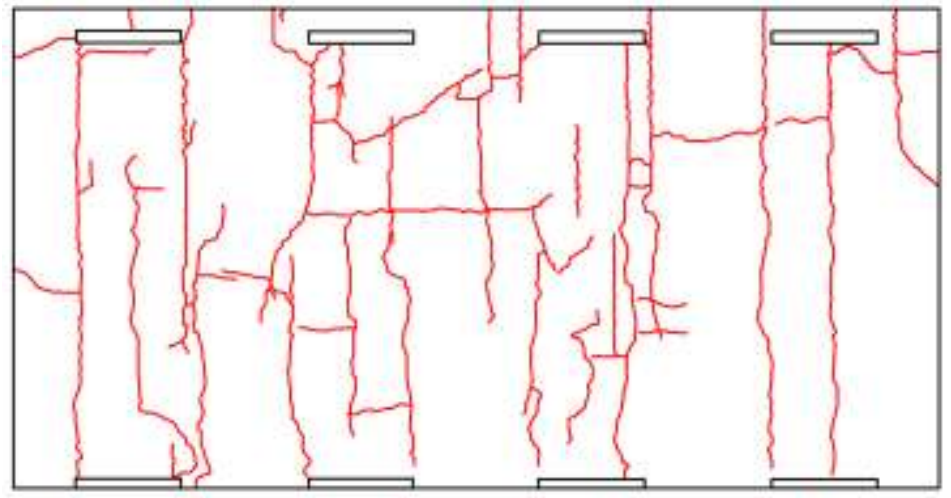

Figure 4 Crack pattern due to corrosion 569 days after casting (prior to impact testing).

To correlate the observed deterioration under accelerated conditions to real field conditions a study was performed by Attar (2016) using the same experiments described in this paper. Three different locations in the U.S. were considered for the casks as the environmental exposure conditions make a significant impact on the deterioration. Using existing available models for steel corrosion in concrete, it was found that the level of deterioration observed prior to impact testing of the casks corresponds to anywhere from 72 years to 300 years of service life. More details about these results is provided in Attar (2016).

\subsection{Instrumentation and test setup}

A CompactDAQ (NI 9188) data acquisition system from National Instruments (2016) equipped with NI 9237 and NI 9234 modules for strain and acceleration measurements, respectively, having a 50kS/s sampling rate was used for data collection. Based on a review of previous experiments and computational studies (Kim et al., 2006), the duration of the tip-over test was estimated to be between approximately 5 milliseconds to 20 milliseconds. With the mentioned system setup, in a 10 millisecond acquisition window, about 500 data points can be recorded, which was deemed sufficient for extracting the dynamic response of the specimens. Eight uniaxial accelerometers (type 42A13, analog, sensitivity equal to $10 \mathrm{mV} / \mathrm{g}$, and range up to $500 \mathrm{~g}$ ) from MEGGITT (Meggitt Sensing Systems, 2016) were used during a given test. A Krypton K610 non-contact dynamic measurement system from Nikon (2016) was 
used to record the displacement at two locations on the cask as a redundant measurement. The system consisted of three cameras, a controller and light-emitting diodes (LEDs), which were attached to the desired measurement locations. The displacement of the LEDs was tracked with a measurement accuracy of up to $60 \mu \mathrm{m}$ during the tests. A sampling frequency of $775 \mathrm{~Hz}$ was used for recording of two LEDs installed on the top and mid-height of the cask. Figure 5 shows the locations of the accelerometers and LEDs mounted on the casks.

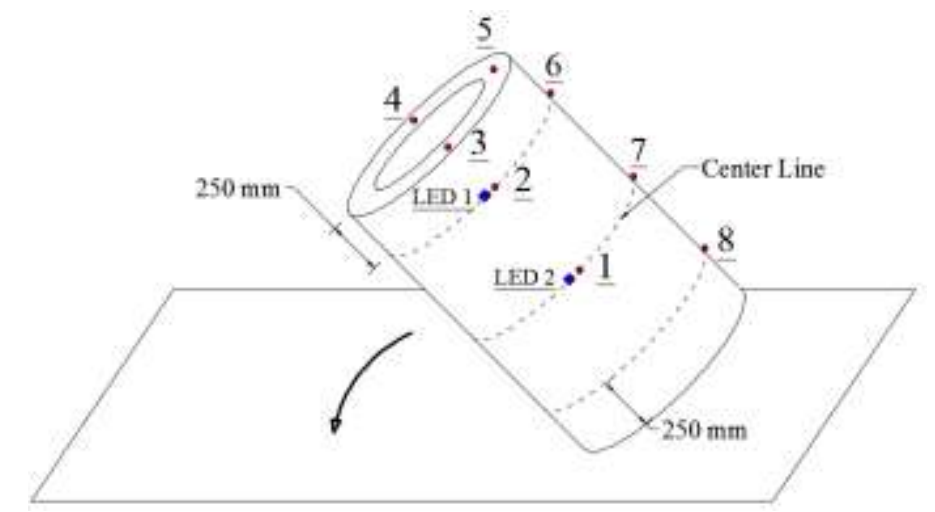

Figure 5 Acceleration sensor locations (note: accelerometers are shown with a dot and LEDs with a diamond.)

Twenty-two strain gages form Kyowa (2016) and twelve rebar gages from HPI (HITEC Products Inc., 2016) (all 120 ohms, quarter bridge, weldable, waterproof) were used in the vertical and circumferential reinforcement, and on the surface of the lid, liner, and base plate, respectively, as shown in Figure 6. Theoretically, three strain gages are needed in order to obtain surface strain (and stress through an assumed elasticity matrix) components at a specific location. However, due to the symmetry of the model cask about the plane passing through the impact line and the absence of shear at the installation locations (see Figure 6), two perpendicular strain gages are installed on the plate surfaces (i.e., lid, liner and base) to obtain the principal strains (see Figure 7(a)). In addition to the base-plate liner and the lid, strain gages were positioned at three different elevations along the height of the cask on the rebar gages (see Figure 6 and Figure 7(b)). Based on the geometry of the model cask, two impact scenarios were considered. The two impact sides were different due to the presence of the air vents on the second impact side. It was observed from the tests that the accelerations are not significantly affected from the damage accumulation due to repeated impact. Therefore, the results from the second (impact side 1 ) and third tests (impact side 2) were used to verify the results and the differences in the damageability of the cask when tipped over in different directions. The records presented in this study are all from the test performed on the impact side one. The results presented below mostly belong to first impact test (impact side 1). 


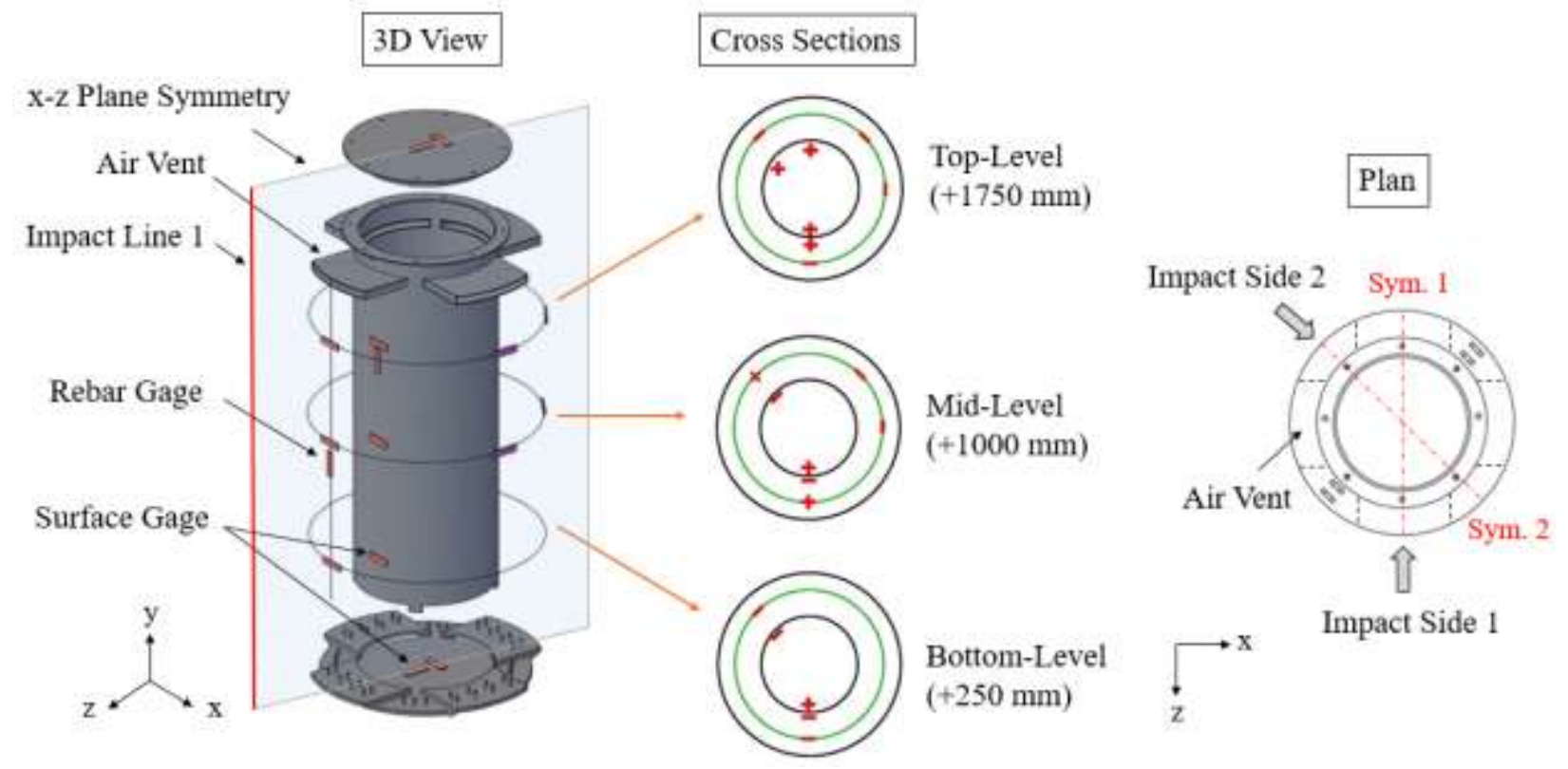

Figure 6 Schematic layout of strain gages for the specimens (note: cross symbols mean gages positioned both in vertical and horizontal directions). The symmetry (sym.) planes are shown in plan view.
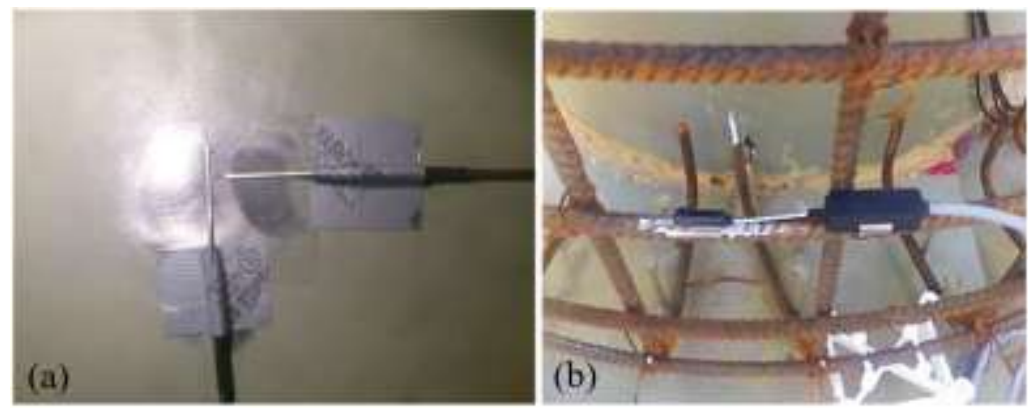

Figure 7 (a) Orthogonal welded surface gages, (b) rebar gages.

A 10 ton gantry crane and a release hook paired with a hydraulic pump were used to lift and release the cask. The test setup including the release hook and the measurement systems is shown in Figure 8 . The casks were released from 45 degree in all tests for consistency. 

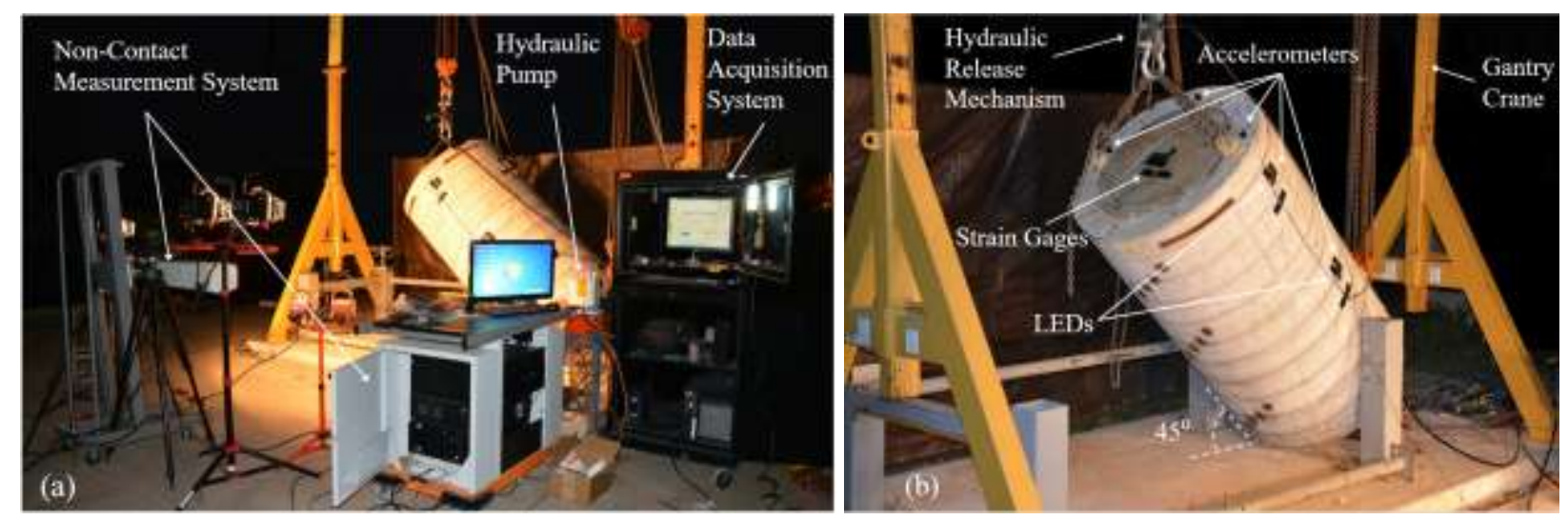

Figure 8 (a) Measurement systems and (b) test setup and sensor locations.

\section{Analytical Solution}

The center of gravity is approximately located at the mid-height of the model. The mass of the specimen is about $7800 \mathrm{~kg}$ including $4600 \mathrm{~kg}$ weight of the cask and $3200 \mathrm{~kg}$ weight of the canister. The mass moment of inertia of a solid cylinder and thick-walled cylindrical tube are given by

$$
\begin{gathered}
\mathrm{I}_{\mathrm{x}}=\mathrm{I}_{\mathrm{y}}=\frac{\mathrm{m}}{12}\left(3 r^{2}+\mathrm{h}^{2}\right) \\
\mathrm{I}_{\mathrm{x}}=\mathrm{I}_{\mathrm{y}}=\frac{\mathrm{m}}{12}\left(3\left(\mathrm{r}_{2}^{2}+\mathrm{r}_{1}^{2}\right)+\mathrm{h}^{2}\right)
\end{gathered}
$$

where $m$ is the mass, $r$ is the solid cylinder radius, $h$ is the cask height and $r_{1}$ and $r_{2}$ are inner and outer radius of the tube as showed in Figure 9.

(a)

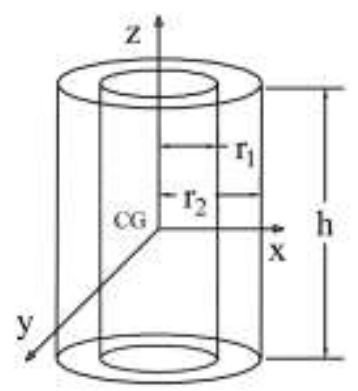

(b)

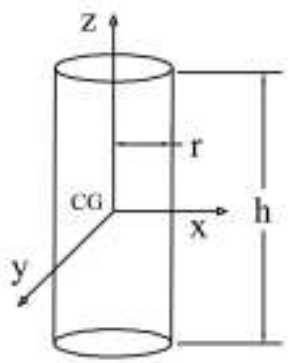

Figure 9 Assumed geometry of the (a) cask and (b) canister

The calculated moment of inertia in the above equations is around the axis passing through the center of gravity. By using the parallel axis theorem, the moment of inertia about the pivot point, is calculated as

$$
\mathrm{I}_{\text {pivot }}=\mathrm{I}+\mathrm{mR}^{2}
$$

where $R$ is the distance between the parallel axes (see Figure 10). The $R$ value is the same for cask and canister since it is assumed the CG of the cask and the canister are the same. The angular velocity, $\omega$, of the cask right before impact then can be found from the conservation of energy according to 


$$
\mathrm{m}_{\text {cask }} \mathrm{g} \Delta \mathrm{h}+\mathrm{m}_{\text {canister }} \mathrm{g} \Delta \mathrm{h}=\frac{1}{2} \mathrm{I}_{\text {cask }} \omega^{2}+\frac{1}{2} \mathrm{I}_{\text {canister }} \omega^{2}
$$

Using Eqn. (4) angular velocity at the impact moment is

$$
\omega=\sqrt{\frac{2 \mathrm{Mg} \Delta \mathrm{h}}{\mathrm{I}_{\text {cask }}+\mathrm{I}_{\text {canister }}}}=2.26 \mathrm{rad} / \mathrm{sec}
$$

where $g$ is the gravitational acceleration and $\Delta h$ is the displacement of the cask center of gravity from initial (Figure 11(b)) to final position (Figure $11(d)$ ) and $M$ is total weight of the system. The vertical velocity $v_{y}$, at the time of impact, along a line passing through the center line of the cask is calculated as $v_{y}=R \times \omega \times \cos (\theta)$ (see Figure 10).

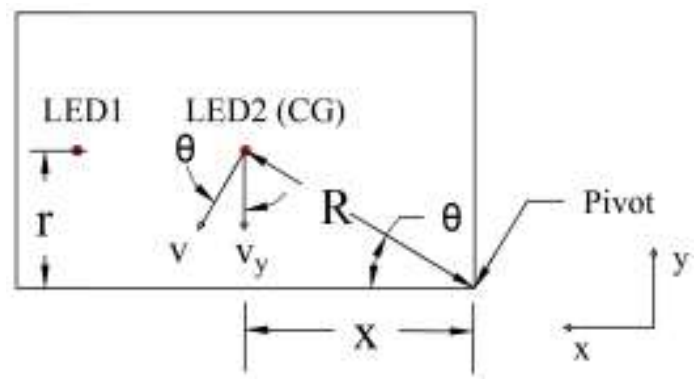

Figure 10 Geometry of the cask (CG is center of gravity).

(a)

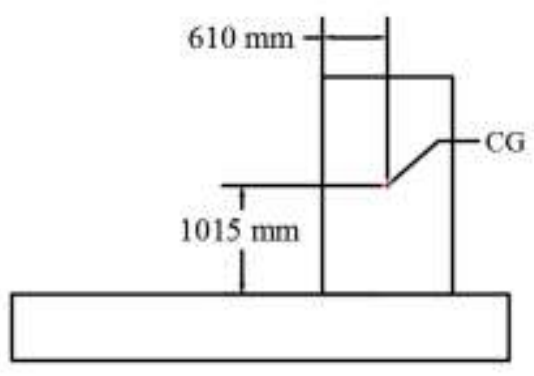

(c)

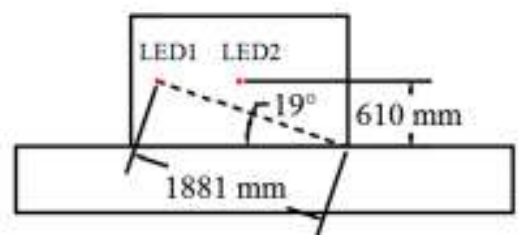

(b)

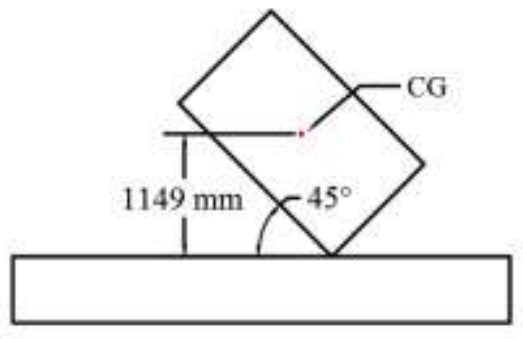

(d)

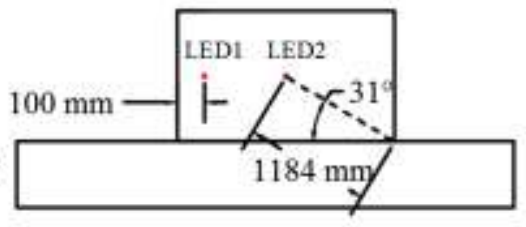

Figure 11 Center of the gravity in various positions (a) standing (b) test initial, (c) and (d) test final.

Using Eqn. (5), the vertical velocities of the cask at the locations of LED1 and LED2 are estimated for both casks. The measured velocity using the non-contact measurement system was found comparable with the velocity calculated according to Eqn. (5) as shown in Table 7, with a better match at the center of gravity of the cask. 
Table 7 Comparison of the measured and calculated velocity.

\begin{tabular}{|c|c|c|c|}
\hline \multirow{2}{*}{$\begin{array}{c}\text { Velocity } \\
(\mathrm{mm} / \mathrm{sec})\end{array}$} & \multicolumn{2}{|c|}{ Measured Velocity } & Calculated Velocity \\
\cline { 2 - 4 } & Control & Aged & 4135 \\
\hline LED1 & 4153 & 4082 & 2293 \\
\hline
\end{tabular}

\section{Results}

\subsection{Processing of dynamic signals}

As explained earlier, eight accelerometer were used in the impact tests as shown in Figure 5. As expected, three of the sensors $(3,4$, and 5$)$ measured the highest decelerations during the test. Sensors 2 and 6 are important for canister design since they are at the same level as the canister top and therefore give an estimate of the maximum deceleration experienced by the canister. The sensor measurements include a range of frequencies and the peak acceleration is not a direct indication of the applied load on the specimen. The signal contains free vibration and resonance of the cask in different modes with relatively high frequencies as well as measurement noise. Filtering helps remove the unwanted high frequency noise.

Note that higher cutoff frequencies cause less distortion of the amplitude; however, they result in a lower signal-to-noise ratio. Therefore, identification of an optimal cutoff frequency and filter parameters is an important issue. Fast Fourier transform (FFT) is applied to the acceleration results to identify a suitable cutoff frequency. Figure 12(a) shows an example acceleration recording in the frequency domain. It is seen that most of the recorded data with high power amplitude are in the range from $0 \mathrm{~Hz}$ to $300 \mathrm{~Hz}$, and there is no significant frequency content beyond $10 \mathrm{kHz}$. According to the NyquistShannon theorem, the required sampling rate should be at least twice of the highest frequency in the signal. Therefore, $50 \mathrm{kHz}$ sampling rate and $300 \mathrm{~Hz}$ cutoff frequency were found to yield an accurate representation of the cask accelerations. A $6^{\text {th }}$ order low-pass Butterworth filter with $300 \mathrm{~Hz}$ cutoff frequency was used to identify the peak acceleration. The filtered and unfiltered measured data for Sensor 4 which recorded the maximum acceleration during the first test of control cask are presented in Figure 12(b).
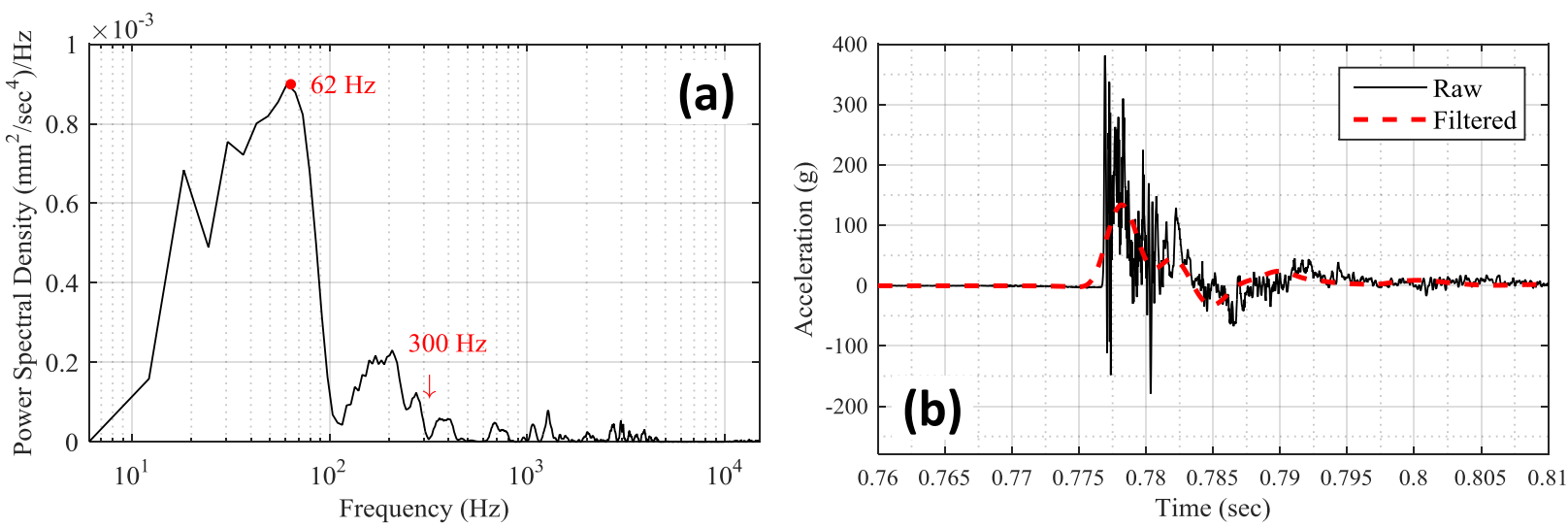
Figure 12 (a) Power spectral density (b) raw and filtered acceleration for Sensor 4, control cask.

\subsection{Acceleration measurements}

A sample time history of accelerations from one of the accelerometers is previously presented in Figure 12(b). Example results obtained from the non-contact measurement system including displacement, velocity and acceleration at CG are presented in Figure 13 to Figure 15. Note that the system measures only the displacement, and the velocity and acceleration were obtained by numerical differentiation of the vertical displacement with respect to time. No filtering was applied to non-contact measurements.
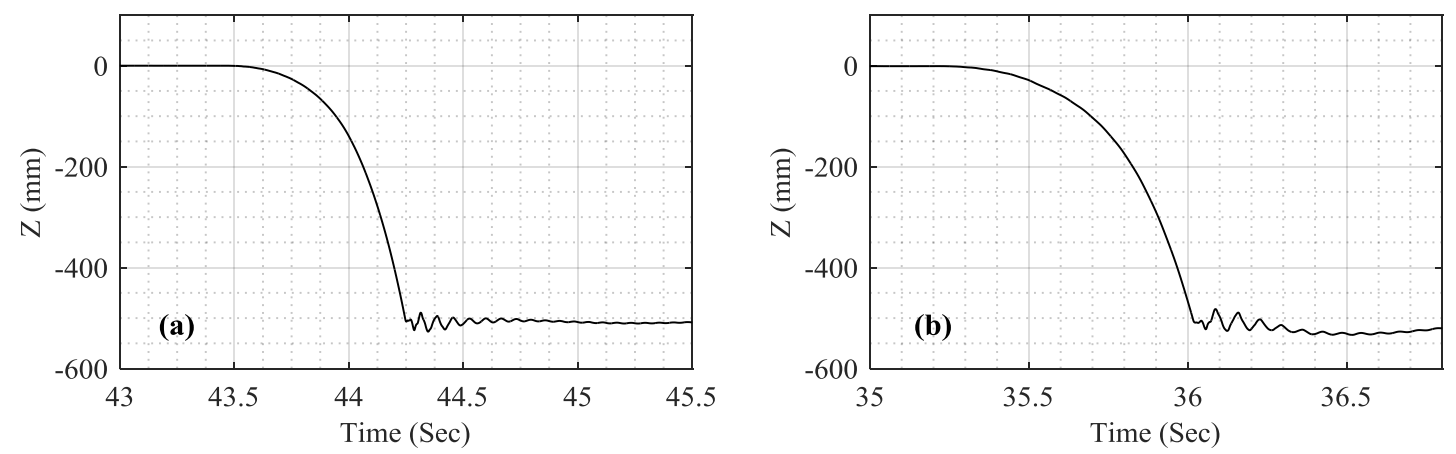

Figure 13 Vertical displacement time history from non-contact measurement (a) control (b) aged
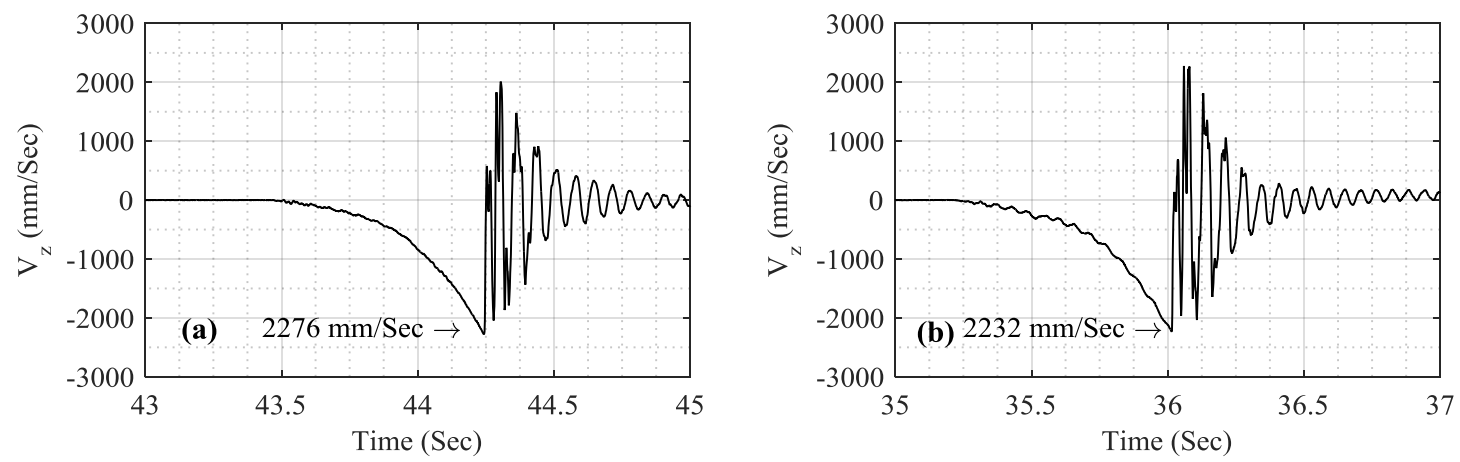

Figure 14 Vertical velocity time history from non-contact measurement location (a) control (b) aged
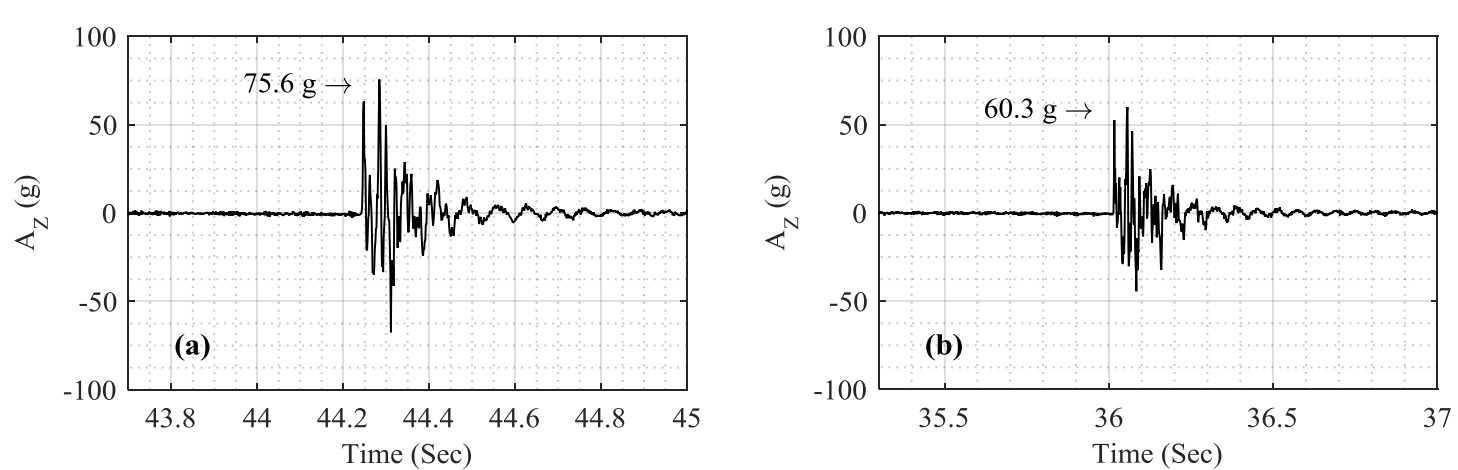

Figure 15 Vertical acceleration time history from non-contact measurement (a) control (b) aged cask.

The tip-over impact consists of multiple impacts due to bouncing of the cask. The most important impact is the first one which has the highest amplitude. Due to material damping and other sources of 
energy dissipation, the secondary impacts have lower amplitude compared to the first impact. The duration of the first impact could be measured using the velocity time history. It is equal to twice the time period between the occurrence of maximum velocity and the subsequent first zero crossing of velocity. As presented in Figure 16, the impact duration is calculated as $\Delta t=2 x\left(T_{2}-T_{1}\right)=15.4 \mathrm{~ms}$ and 18.0 $m s$ and for the control and aged casks, respectively.
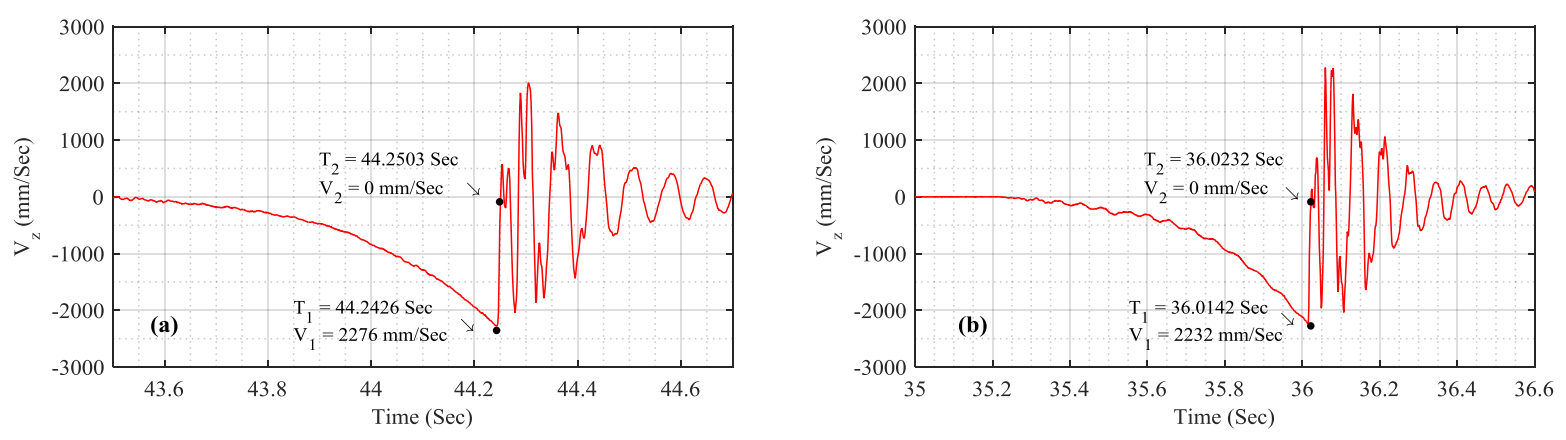

Figure 16 Estimation of the impact duration from velocity time-history (a) control (b) aged cask.

The impact duration is at $64 \mathrm{~Hz}$ and $55 \mathrm{~Hz}$ for control and aged cask, respectively. It could be concluded that the main impact pulse is applied at this frequency and therefore application of low-pass filter with a $300 \mathrm{~Hz}$ cut-off frequency is acceptable. A summary of the filtered peak deceleration from all the accelerometers as well the results obtained from the non-contact measurement system are presented in Figure 17.

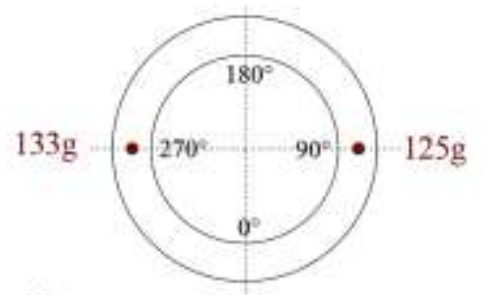

(a)

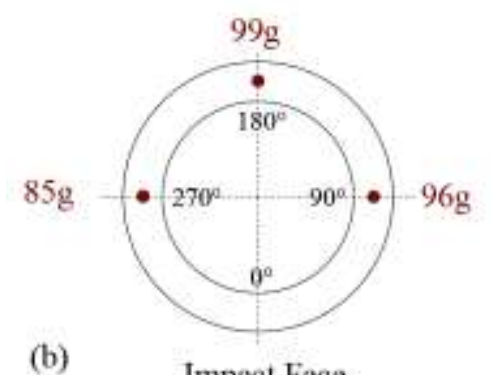

Impact Face
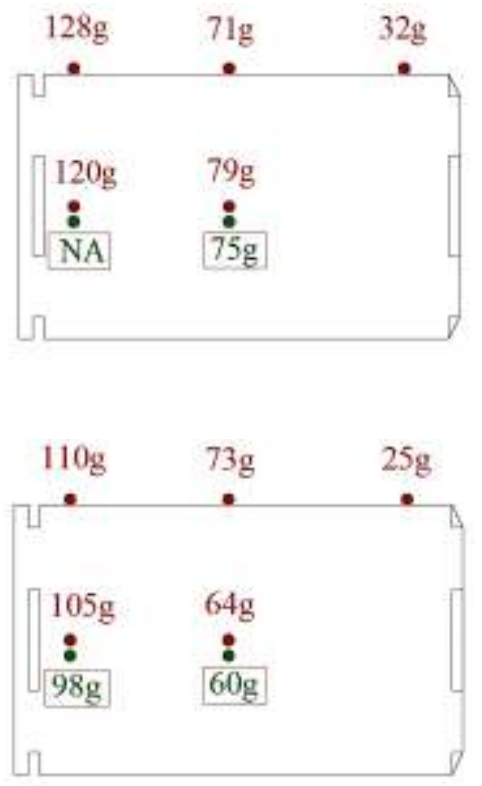

Figure 17 Filtered peak acceleration, (a) control (b) aged (boxed values were obtained from the noncontact measurements system while the unboxed values were obtained from the accelerometers). Due to a technical problem, the result for LED2 for control cask is not available. 
The results shown in Figure 17 are obtained from the tip-over test for both casks. The acceleration values are observed to be lower for the aged cask. Sensors 2 to 6 are the most important sensors since they experience the highest acceleration. The average peak deceleration measured in sensors 2 to 6 (closer to the top of the casks) in the aged cask is $21 \%$ less than the control cask. This could be attributed to the higher structural stiffness of the control concrete and more energy dissipation through the distributed cracks on the aged cask. The stored kinematic energy for the casks were the same as both were released from 45 degree angle and the total weight was the same for both casks. Therefore, the two sources for dissipation of the kinematic energy could be considered as: (1) inelastic deformation of the subgrade soil, and (2) cracking and damage of the cask and the pad. As discussed earlier, the pad remained elastic during testing and plastic deformation of the soil was minimized. Therefore, the main source of energy dissipation was the damage and deformation of the cask. This fact confirms that the structural stiffness of the cask has the most important contribution to the deceleration during impact. Furthermore, the impact duration calculated in the previous section was $17 \%$ larger for the aged cask. Considering the momentum equation:

$$
F t=m V
$$

in which, $F, t, m$, and $V$ are the impact force, impact duration, mass, and velocity, respectively, since the impact velocity and momentum are the same for the aged and control cask as shown in the analytical solution section, the aged cask with a higher impact duration, experiences less average impact force.

\subsection{Strain measurements and yield criterion}

As explained previously, the strain was measured on the rebar, liner, base-plate and the lid. It is required to translate the strain values measured from the experiments to a stress-based engineering measure which can be used to evaluate the performance of the structure during the impact. Thus, it is necessary to perform this conversion in the framework of a constitutive relation. The von Mises yield criterion is used to evaluate the stress level of the steel material at each point which is given as

$$
\sqrt{\sigma_{11}^{2}-\sigma_{11} \sigma_{22}+\sigma_{22}^{2}+3 \sigma_{12}^{2}} \leq \sigma_{y}
$$

where $\sigma_{11}, \sigma_{22}$ and $\sigma_{33}$ represent the stress values in $x, y$ and $z$ directions, respectively. Since the ratio of the diameter to thickness of the lid is about 44, it was assumed that the magnitude of the out of plane component of stress is negligible compared to the in plane components. Thus, the equations for plane stress condition are valid for this type of components and were used to define the stress components. As an example, the calculated von Misses stresses using the measured strain obtained from two prependicular strain gages installed to center of the lid are shown in Figure 18 as a function of time. The maximum stress for the aged and control cask was found as $132 \mathrm{MPa}$ and $87 \mathrm{MPa}$, respectively, which are about $37 \%$ and $24 \%$ of the yield strength of the steel. From these results, it is concluded that the yielding in lid steel was not observed. 


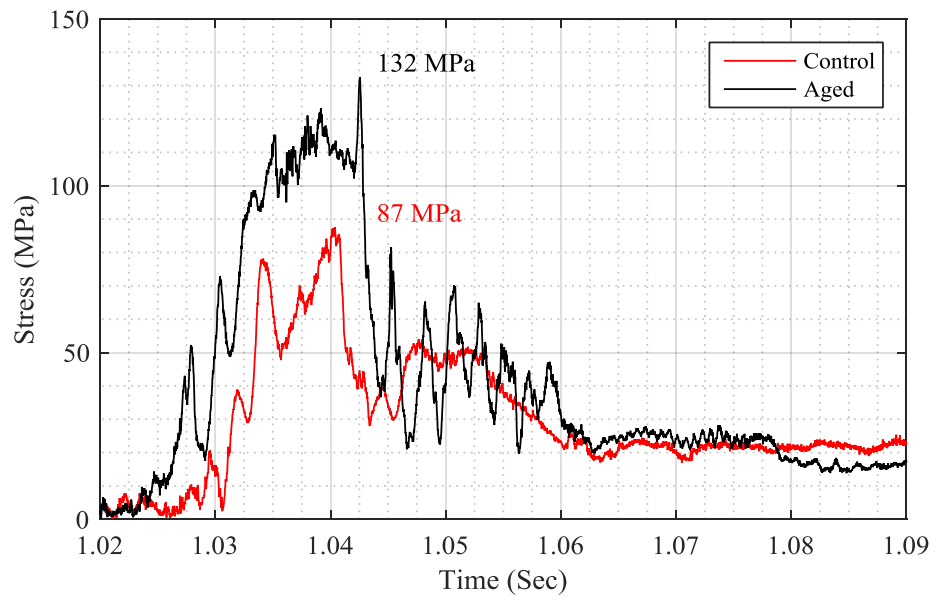

Figure 18 von Misses stress at the center of the lid center.

Similar principles were used to determine whether yielding had occurred at other locations of the casks. Figure 19 shows the calculated von Mises stressed based on the measured strain data. If yielding had occurred, it is indicated as "yield" rather than the actual value of stress because the strain data from the strain gages lose reliability once yielding occurs and the actual value of the stresses is less critical for the assessment. The measured strain at different locations along the height of the liner on the impact side shows that yielding occurred in both specimens.
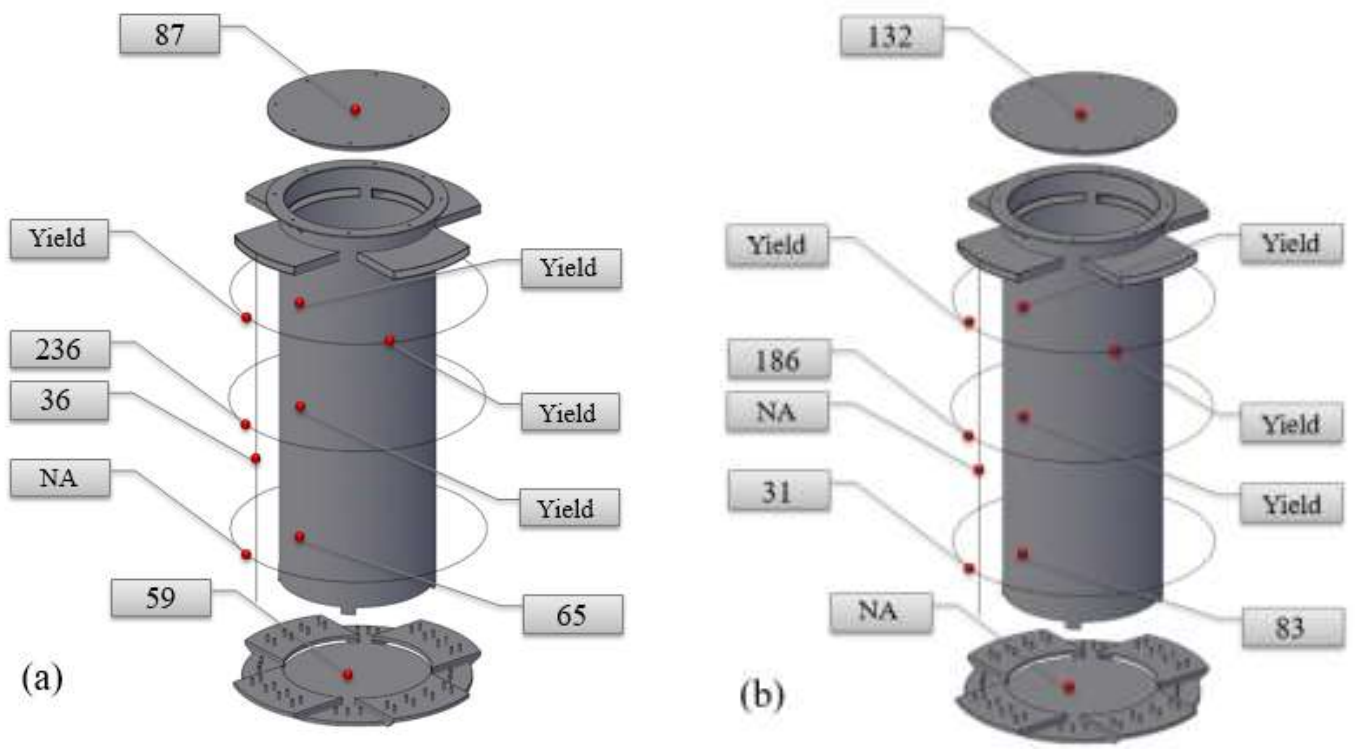

Figure 19 Calculated von Mises stress (MPa) for (a) control cask (b) aged cask. NA indicates that the results were not available due to sensor failure.

When the corroded steel rebar are located in the tensile zone, the bending stiffness of the section is reduced due to the loss of cross section and bond strength (Castel et al., 2000, El Maaddawy et al., 2005). It was previously shown that $9 \%$ area loss due to steel corrosion can increase the deflection of a reinforced concrete beam by 1.5 times (Cabrera, 1996). While direct measurement of the cask 
deformation at the impact moment was not available, it could be concluded that the aged cask experienced higher deformations. Yielding was observed at the top circumferential rebar while the stress level in the vertical reinforcement was limited and no yielding is expected. The stresses in the vertical rebar are an indication of the shear forces.

\subsection{Damage evaluations: crack width and pattern and failure mode}

In order to evaluate the level of damage, the cracks were marked and recorded after testing. Crack patterns were mapped manually from photos of each specimen after the first tip over test is presented in Figure 20. Note that the cracks were already developed on the surface of the aged cask prior to the test. Therefore the quantity of additional cracks from the impact (thicker lines in Figure 20) is less than control casks due to energy dissipation through deformations at the existing cracks as explained below.

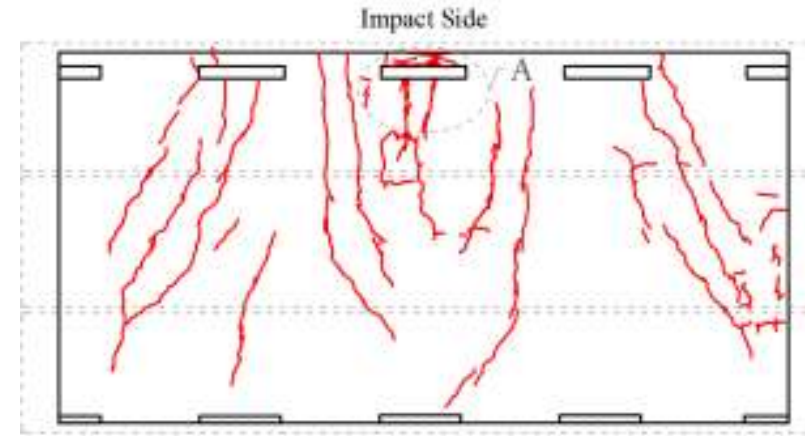

(a)

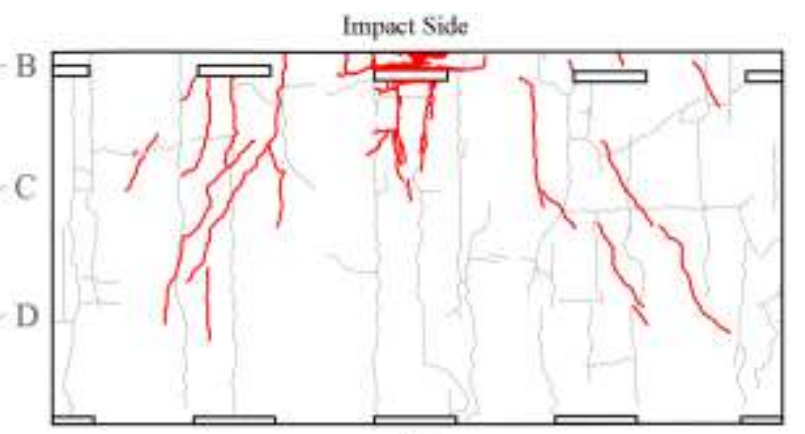

(b)

Figure 20 Residual crack patterns due to tip over after Test 1 on the (a) control (b) aged cask. Regions with different deformation/damage patterns are labeled $A$ to $D$ in part (a). The faint lines in part (b) are the existing cracks due to corrosion damage.

In addition, the width of the cracks was measured at several locations using a 10x magnifier before and after the tests. Summary of the maximum crack widths before and after the first tip-over test are provided in Table 8 and Figure 21. Note that no cracks was observed on the control cask prior to the test.

Table 8 Maximum crack widths prior to and after first tip-over test.

\begin{tabular}{|c|c|c|c|}
\hline \multirow{2}{*}{} & \multicolumn{3}{|c|}{ Crack Width (mm) } \\
\cline { 2 - 4 } & Control & \multicolumn{2}{|c|}{ Aged } \\
\cline { 2 - 4 } & Post & Prior & Post \\
\hline Top & 1.85 & 0.93 & 5.11 \\
\hline Side & 1.61 & 1.46 & 2.68 \\
\hline
\end{tabular}

The crack density could be visually compared on the top and the side of the cask in Figure 22 and Figure 23 , respectively. 

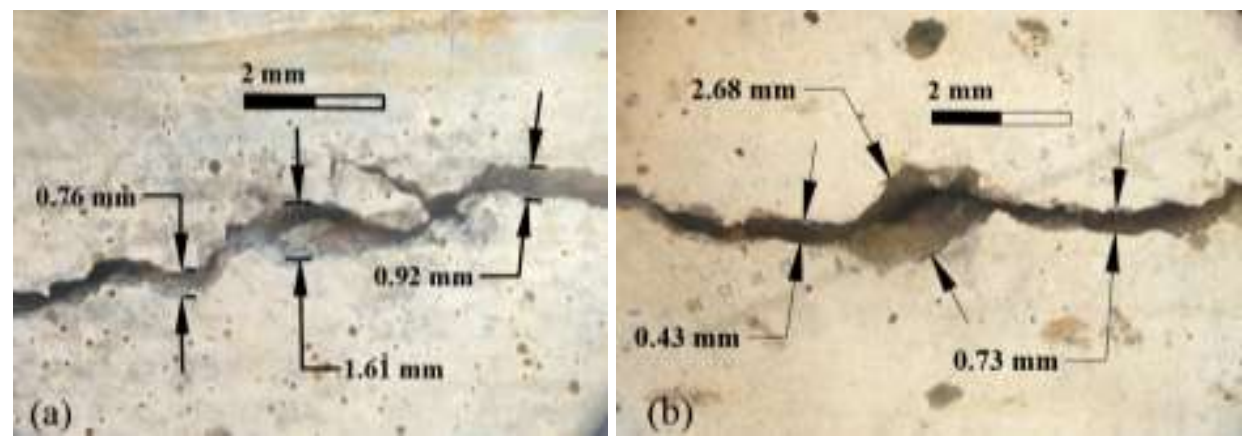

Figure 21 Maximum crack width on the side due to impact (a) control (b) aged cask.
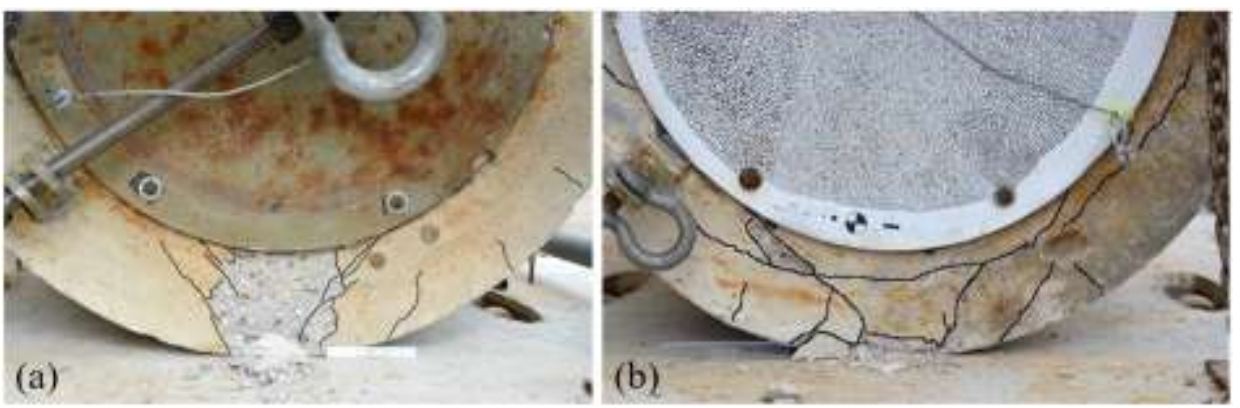

Figure 22 cracking of casks at the top surface (a) control cask (b) aged cask.

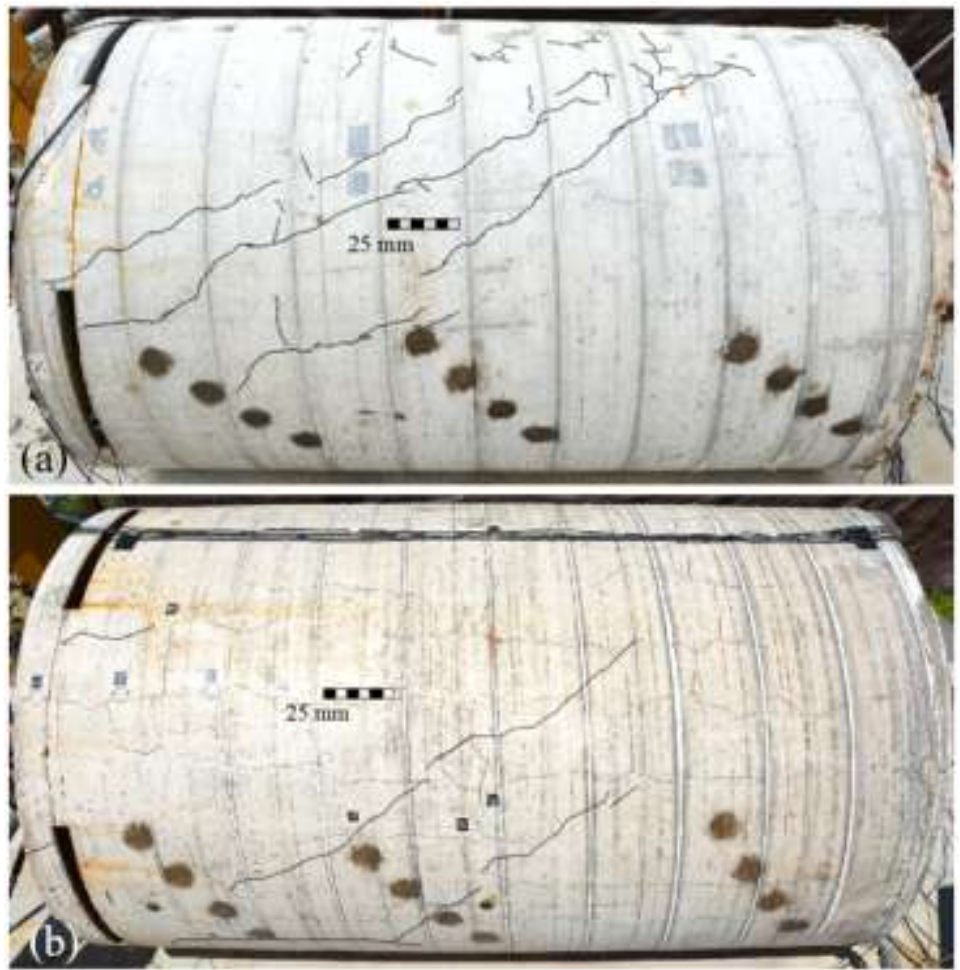

Figure 23 Inclined cracks formed on cask body (a) control cask (b) aged cask

Damage investigation of the casks showed four types of failure in the tip-over incident. The first mode is the compressive crushing which occurs at the top of the cask on the impact side indicated as zone $A$ in 
Figure 20(a). This part is sandwiched between the pad and the canister. In the other words, the impact force is transferred through this part of the cask outerpack to the canister. The spalling is only observed in zone $A$ and it was more severe for the aged cask. Compressive strength of concrete is the most important parameter for this failure mode. While the addition of the chloride ions to the mixture helps achieve high levels of corrosion damage in a short period of time, a reduction of $24 \%$ and $31 \%$ was observed, respectively, in compressive and split tensile strength at 28 days (see Table 6 ). This may have affected the response of the cask especially in zone $A$ where compressive crushing is the main mode of failure. The damage and crack pattern observed in zone A could be attributed to the compressive strength reduction and cover cracking due to rebar expansion developed prior to the test. However, since the overpack concrete is confined by the rebar cage, steel liner and base plate, the strength reduction due to the chloride addition was not seen to largely affect the overall structural response of the cask. The effect of chloride ions on the mechanical properties of the fresh and hardened concrete is discussed in detail in Attar (2016).

The second mode is the flexural failure (zone B in Figure 20(a)). The cracks at the upper parts were mostly vertical, which are an indication of a flexural failure. In the mid-height (zone $C$ ) the cracks were more inclined, indicating of a shear failure which is the third mode. Both shear and flexural failure modes were seen in zone $C$. Reinforcement ratio is the most important factor for the second and third modes of failure. Only inclined cracks with less density and width were observed in zone $D$ since the impact force is minimum in this zone and mainly governed by shear. Overall, the density of cracks due to impact was lower in the aged cask. The distributed corrosion cracks had already developed in the aged cask along the reinforcement prior to the tests. It may be assumed that the cracks that could develop due to impact were already present due to corrosion in zone B. However, the cracks were inclined (as opposed to horizontal and vertical cracks due to corrosion) at the mid-height (zone C), indicating the same failure mode as in the control cask. The impact side did not have significant effect on the results except some deformation of the air outlet and crushing of the concrete was observed above the vent (see Figure 24).
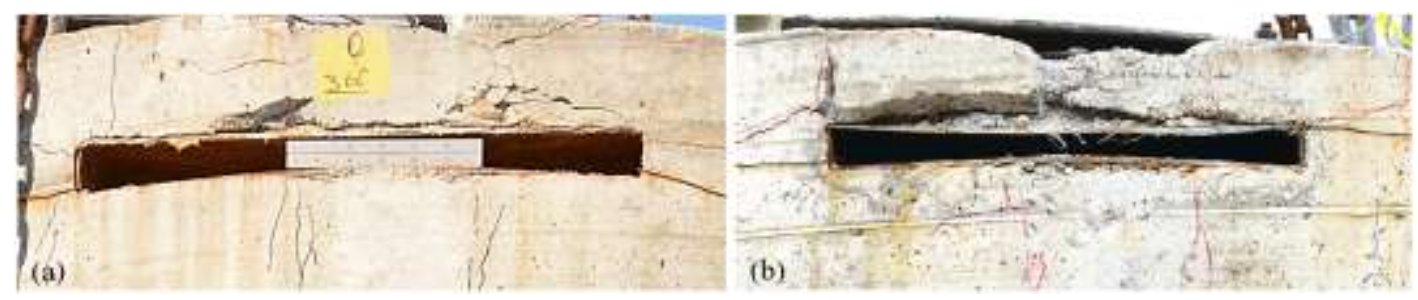

Figure 24 Top air vent deformation of the aged cask (zone A) (a) control (b) aged cask.

As mentioned earlier, additional tip over tests were performed on the specimens to verify the consistency of the results (mainly the acceleration measurements). The impact orientation did not have a significant effect on the results. The control cask showed some minimal increase in damage after two additional tests. On the contrary, the concrete cover on the top of the aged cask was shattered and a large portion of concrete cover was removed during a third test due to the impact force (see Figure 25). 


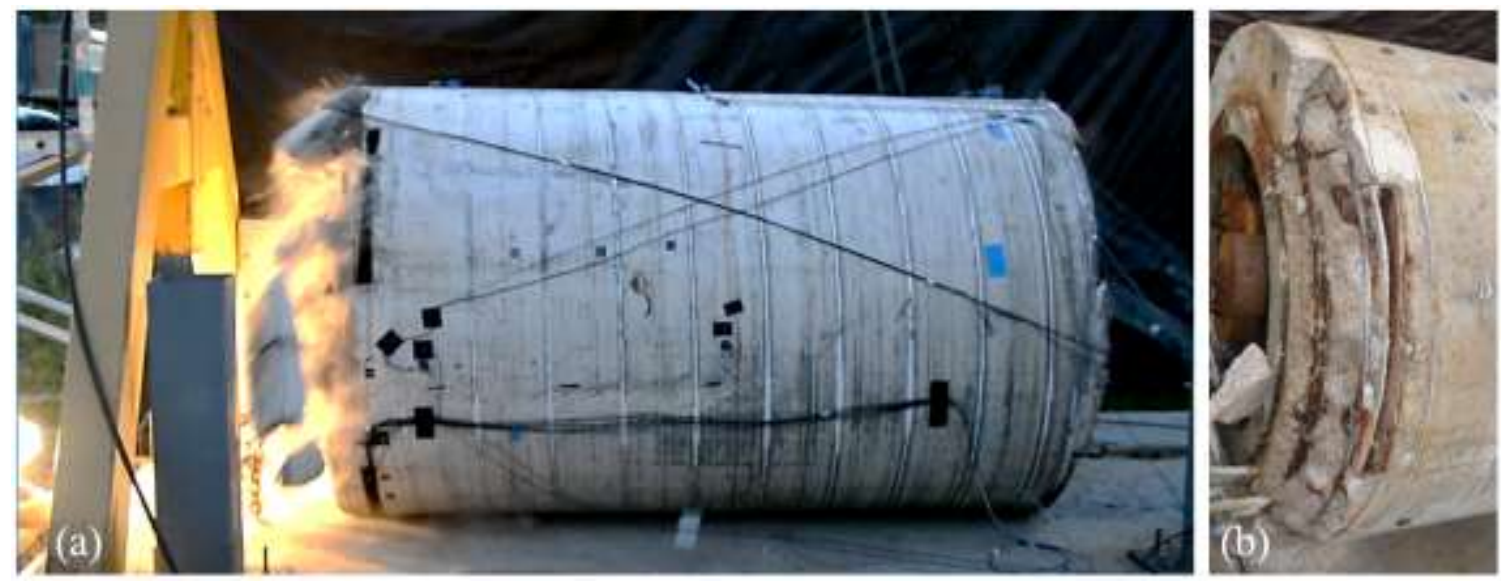

Figure 25 Spalling (a) at the impact moment of the aged cask (impact side 2), (b) condition after the test.

\section{Conclusions}

The performance of corrosion-damaged vertical concrete casks in the event of a tip-over impact was studied using two 1/3-scale specimens (control and aged). An accelerated steel corrosion procedure was developed and applied on one of the specimens by adding a chemical agent to the concrete admixture. The cask was allowed to age for a two years period. The corrosion progress was monitored via visual inspection and non-destructive tests. After two years, tip-over tests were performed on each cask and the following conclusions were drawn:

- The casks maintained their overall structural integrity even after three consecutive impact tests. The level of structural damage in the aged cask was found to be irreparable, however, the dynamic response was not significantly affected from corrosion. No visual damage or deformation was observed on the mock-up canister after the tests.

- Steel corrosion was found to affect the structural performance of the casks in terms of peak acceleration (and applied impact force) as well as damage to the cask outerpack.

- Lower force and acceleration is experienced by the canister while higher structural damage was observed for the aged cask.

- The average of the acceleration recorded by the sensors in the impact area was $21 \%$ less in the aged cask compared to the control cask.

- The measured strain and consequently stress level was generally higher in the steel components in the aged cask. While the stress level in the lid was below the yield strength, yielding occurred both in the liner and reinforcement at multiple locations for both casks.

- Concrete spalling was observed at the top of the cask which experienced the highest impact load. The spalling was much more severe in the aged cask.

- The maximum crack width observed after 569 days of corrosion exposure on the aged crack was $1.46 \mathrm{~mm}$ with an average of $0.33 \mathrm{~mm}$ over 23 measurement points on the entire surface. The maximum crack width increased to $5.11 \mathrm{~mm}$ after the first impact test.

- Based on the experimental results presented here, the level of corrosion at the time of impact testing of the casks (approximately $9 \%$ area loss in the rebar), does not result in major damage to the concrete overpack to risk the safety of the canister. However, these findings should be taken 
within the limitations of the research, mainly related to the scaling and total weight of the tested casks.

Further research is currently underway to evaluate the potential impacts for the prototype cask configuration.

\section{Acknowledgments}

The financial support for this project was provided by the United States Department of Energy through the Nuclear Energy University Program under the Contract No. 00128931. The findings presented herein are those of the authors and do not necessarily reflect the views of the sponsor.

\section{References}

Abosrra, L., Ashour, A., and Youseffi, M. (2011). "Corrosion of steel reinforcement in concrete of different compressive strengths," Construction and Building Materials, 25 (10):3915-392.

$\mathrm{ACl}$ (2003). Control of cracking of concrete structures, ACl 224R-01, American Concrete Institute, Farmington Hills, MI.

$\mathrm{ACl}$ (2014). Building code requirements for structural concrete and commentary ACl 318-14R, American Concrete Institute $(\mathrm{ACl})$, Farmington Hills, MI.

Ahmad, S. (2003). "Reinforcement corrosion in concrete structures, its monitoring and service life prediction—a review," Cement and Concrete Composites, 25 (4):459-471.

Ann, K. Y., and Song, H.-W. (2007). "Chloride threshold level for corrosion of steel in concrete," Corrosion Science, 49 (11):4113-4133.

Attar A. (2016). "Accelerated alkali-Silica reaction and corrosion of reinforcing steel in concrete: application on dry casks," PhD Thesis, Civil and Environmental Engineering, University of Houston, Houston, Texas.

ASTM (2004). Standard Test Method for Splitting Tensile Strength of Cylindrical Concrete Specimens, ASTM C496 / C496M-11, American Society of Testing Materials (ASTM), West Conshohocken, PA.

ASTM (2014). Standard test method for static modulus of elasticity and poisson's ratio of concrete in compression, ASTM C469 / C469M-14, American Society of Testing Materials (ASTM), West Conshohocken, PA.

ASTM (2015). Standard test method for corrosion potentials of uncoated reinforcing steel in concrete, ASTM C876-15, American Society of Testing Materials (ASTM), West Conshohocken, PA.

ASTM (2016). Standard test method for compressive strength of cylindrical concrete specimens, ASTM C39 / C39M-16b, American Society of Testing Materials (ASTM), West Conshohocken, PA.

ASTM (2016). Standard test method for density (unit weight), yield, and air content (Gravimetric) of concrete, ASTM C138 / C138M-16a, American Society of Testing Materials (ASTM), ASTM International, West Conshohocken, PA.

ASTM (2016). Standard test methods and definitions for mechanical testing of steel products, A370-16, American Society of Testing Materials (ASTM), Conshohocken, PA.

ASTM (2016). Standard test methods for tension testing of metallic materials, ASTM E8 / E8M-16a American Society of Testing Materials (ASTM), West Conshohocken, PA.

Attar, A., Gencturk, B., Hanifehzadeh, M., and Willam, K. (2016). "Accelerated aging of concrete dry cask storage systems for nuclear waste," Journal of Advanced Concrete Technology, 14 (6):299-310.

BASF (2016). MasterPozzolith 200, Available from: https://www.master-builders-solutions.basf.us, Accessed on Dec. 26. 
Cabrera, J. (1996). "Deterioration of concrete due to reinforcement steel corrosion," Cement and concrete composites, 18 (1):47-59.

Castel, A., François, R., and Arliguie, G. (2000). "Mechanical behaviour of corroded reinforced concrete beams-Part 1: experimental study of corroded beams," Materials and Structures, 33 (9):539544.

Cheng, A., Huang, R., Wu, J., and Chen, C. (2005). "Effect of rebar coating on corrosion resistance and bond strength of reinforced concrete," Construction and Building Materials, 19 (5):404-412.

El Maaddawy, T., Soudki, K., and Topper, T. (2005). "Long-term performance of corrosion-damaged reinforced concrete beams," ACl Structural Journal, 102 (5):649.

Ghazanfari, N., and Manafpour, A. (2016). "Flexural behavior of post tensioned beams damaged by reinforcement corrosion before and after applying patch-repair," American Journal of Civil Engineering and Architecture, 4 (5):171-180.

Hitec Products Inc. (2016). Strain gages, Available from: http://www.hitecprod.com/, Accessed on Dec. 26.

Kato, O., and Saegusa, T. (2001). "Long-term containment performance test facilities for spent fuel transport/storage casks (CRIEPI, Japan)," International Journal of Radioactive Materials Transport $12(2-3): 119-122$.

Kim, D.-H., Seo, K.-S., Lee, J.-C., Cho, C.-H., Jang, H.-K., and Choi, B.-I. (2006). "A test for verifying a tip-over analysis of a dry storage cask," Journal of the Korean Radioactive Waste Society, 4 (3):245-253.

Kyowa (2016). KCW Series weldable waterproof foil strain gages, Available from: http://www.kyowaei.com/, Accessed on Dec. 21.

Lee, C., Bonacci, J., Thomas, M. D., Maalej, M., Khajehpour, S., Hearn, N., Pantazopoulou, S., and Sheikh, S. (2000). "Accelerated corrosion and repair of reinforced concrete columns using carbon fibre reinforced polymer sheets," Canadian Journal of Civil Engineering, 27 (5):941-948.

Liu, T., and Weyers, R. (1998). "Modeling the dynamic corrosion process in chloride contaminated concrete structures," Cement and Concrete Research, 28 (3):365-379.

Marsh, G., and Taylor, K. (1988). "An assessment of carbon steel containers for radioactive waste disposal." Corrosion science, 28 (3):289-320.

Meggitt Sensing Systems (2016). 42A accelerometers, Available from: https://www.endevco.com/, Accessed on Dec. 26.

National Instruments (2016). CompactDAQ, Available from: http://www.ni.com/en-us.html, Accessed on Dec. 26.

Nikon (2016). K-Series Optical CMM, Available from: http://www.nikonmetrology.com/en_US/Products/Portable-Measuring/Optical-CMM/K-SeriesOptical-CMM, Accessed on Dec. 21.

NUREG (2000). Standard review plan for spent fuel dry storage facilities, NUREG-1567, U.S. Nuclear Regulatory Commission, Washington, D.C..

Şahmaran, M., and Li, V. C. (2009). "Durability properties of micro-cracked ECC containing high volumes fly ash," Cement and Concrete Research, 39 (11):1033-1043.

Schießl, P., and Raupach, M. (1997). "Laboratory studies and calculations on the influence of crack width on chloride-induced corrosion of steel in concrete," ACI Materials Journal, 94 (1):56-62.

Shappert, L. (1970). Cask designers guid: a guide for the design, fabrication, and operation of shipping casks for nuclear applications, No. ORNL-NSIC--68, prepared by Oak Ridge National Lab, Oak Ridge, TN.

Shappert, L., and Ludwig, S. (2004). "44 years of testing radioactive materials packages at ORNL," 14th International Symposium on the Packaging and Transportation of Radioactive Materials, September 20-24, Berlin, Germany. 
Shimizu, M., and Hoshikawa, T. (2004). "Dual-purpose transport and storage dry-type metal casks for spent nuclear fuel," Hitachi Review 53 (3):153.

Shoesmith, D. (2006). "Assessing the corrosion performance of high-level nuclear waste containers," Corrosion, 62 (8):703-722.

Song, H.-W., and Saraswathy, V. (2007). "Corrosion monitoring of reinforced concrete structures-a review," International Journal of Electrochemical Science, 2:1-28.

Spencer, D., Edwards, M., Wenman, M., Tsitsios, C., Scatigno, G., and Chard-Tuckey, P. (2014). "The initiation and propagation of chloride-induced transgranular stress-corrosion cracking (TGSCC) of 304L austenitic stainless steel under atmospheric conditions," Corrosion Science, 88:76-88.

Tani, J., Mayuzumi, M., and Hara, N. (2009). "Initiation and propagation of stress corrosion cracking of stainless steel canister for concrete cask storage of spent nuclear fuel," Corrosion, 65 (3):187194.

U.S. NRC (2016). Dry Cask Storage, Available from: https://www.nrc.gov/waste/spent-fuel-storage/drycask-storage.html, Accessed on Dec. 12.

Vecchio, F. J., and Sato, J. A. (1988). "Drop, fire, and thermal testing of a nuclear fuel container," $\mathrm{ACl}$ Structural Journal, $85(4): 374-383$.

Yuan, Y., Ji, Y., and Shah, S. P. (2007). "Comparison of two accelerated corrosion techniques for concrete structures," ACl Structural Journal, 104 (3):344.

Zhou, Y., Gencturk, B., Willam, K., and Attar, A. (2014). "Carbonation-induced and chloride-induced corrosion in reinforced concrete structures," Journal of Materials in Civil Engineering, 27 (9):04014245. 